[When citing this chapter, refer to Behaviour 152 (2015) 285-311]

\title{
Prolonged maximal sexual swelling in wild bonobos facilitates affiliative interactions between females
}

\author{
Heungjin Ryu, David A. Hill and Takeshi Furuichi * \\ Primate Research Institute, Kyoto University, Inuyama, Aichi, Japan \\ *Corresponding author's e-mail address: furuichi@ pri.kyoto-u.ac.jp
}

Accepted 6 May 2014; published online 12 June 2014

\begin{abstract}
Perineal sexual skin swelling in relation to menstrual cycle occurs in a variety of primate taxa. However, sexual swelling with exaggerated size and colour is found only in some Old World monkeys and the two Pan species. Although several hypotheses have been proposed (e.g., reliable indicator hypothesis and graded signal hypothesis), it seems unlikely that a single explanation can account for the significance of the sexual swelling in all of these species. Bonobos (Pan paniscus) provide an excellent opportunity for studying sexual swelling since they have the most prolonged maximal swelling periods among primates. In this study we propose a new hypothesis that sexual swelling in female bonobos increases their attractiveness to other females and thereby facilitates affiliative social interaction with them. We found that free-ranging female bonobos with maximal sexual swelling engaged in affiliative social interactions with other females, including genitogenital rubbing, staying in close proximity and grooming, more frequently than females without maximal swelling. These tendencies suggest that females with maximal swelling were attractive to other females. The results also suggest that the benefits of maximal swelling might vary among females depending on their life-history stage. In particular, young females may get more benefits from prolonged maximal swelling through increased grooming reciprocity and staying in close proximity to other females. Thus our study supported the hypothesis that one function of prolonged maximal swelling in bonobos is to increase attractiveness to other females, thereby enhancing affiliative relationships between females in a male-philopatric social system.
\end{abstract}

\section{Keywords}

sexual swelling, female bonobos, life-history, social interactions.

\section{Introduction}

The term sexual swelling is used to describe swelling of the skin of the perineum in relation to the menstrual cycle of females. It has been described in a variety of primate species including prosimians (e.g., ring-tailed lemur, 
Lemur catta (Jolly, 1966), and Horsfield's tarsier, Tarsius bancanus (Wright et al., 1986)), Old World monkeys (e.g., Japanese macaques, Macaca fuscata (Tokuda, 1961) and baboons, Papio hamadryas (Pocock, 1906)), and ape species (e.g., bonobos, Pan paniscus (Savage-Rumbaugh \& Wilkerson, 1978; Kuroda, 1980) and chimpanzees, Pan troglodytes (Zuckerman \& Fulton, 1934)).

Sexual swelling of very conspicuous size and colour, which has been described as 'exaggerated sexual swelling' (Nunn, 1999), is found only in several Old World monkey species and the two Pan species. In the rest of this paper, the term 'sexual swelling' is used synonymously with Nunn's (1999) definition of the exaggerated sexual swelling. It has also been suggested that this conspicuous sexual swelling has evolved independently in Old World anthropoids at least three times (Dixson, 1983; Nunn, 1999). In many species, sexual swelling reaches its maximal size near ovulation (e.g., Macaca nigra (Dixson, 1977); Papio anubis and Papio cynocephalus (Hendrickx \& Kraemer, 1969); and Pan troglodytes (Dahl et al., 1991)) and most mating activity is concentrated in the maximal swelling periods (Saayman, 1970; Furuichi, 1987; Bercovitch, 1988; Wallis, 1992; Young et al., 2013). Sexual swelling is thought to incur some cost for females, such as possible hindrance of metabolism from water retention (Nunn, 1999), increased chance of injuries (Hausfater, 1975) and increased body weight (Bielert \& Busse, 1983), which can increase the energetic cost of locomotion (Nunn, 1999). Therefore, it is assumed that there must also be advantages to females of having sexual swelling that outweigh the costs (Nunn, 1999; Zinner et al., 2004; Alberts \& Fitzpatrick, 2012).

Several hypotheses have been proposed to explain the function and evolution of sexual swelling in the context of female reproductive strategies. Some researchers have suggested that sexual swelling invokes frequent promiscuous mating and inter-male competition that are beneficial for females (the best-male hypothesis (Clutton-Brock \& Harvey, 1976); many-male hypothesis (Hrdy \& Whitten, 1987)). Others have suggested that the sexual swelling encourages dominant males to mate-guard and recognize paternity by accurately indicating the timing of ovulation, and thus to provide support for the females and/or offspring (obvious-ovulation hypothesis (Hamilton, 1984); male-services hypothesis (reviewed in Nunn, 1999); and paternal care hypothesis (Alberts \& Fitzpatrick, 2012)). Other explanations include a comprehensive hypothesis which puts together the functions of sexual swelling 
derived from several hypotheses (graded signal hypothesis; Nunn, 1999) and the reliable quality indicator hypothesis (Pagel, 1994) which assumes that sexual swelling may indicate reproductive value of females. Furthermore, some groups of researchers have suggested variations of a social passport hypothesis. For example, that sexual swelling facilitates between-group transfer of adolescent females by showing resident males their oestrous status (Anderson \& Bielert, 1994), increases support from males in female-female competitive situations especially during immigration (Boesch \& BoeschAchermann, 2000), or helps female-female interactions (Paoli et al., 2006). However, it seems unlikely that a single benefit inferred from a single hypothesis could account for all aspects of the phenomenon in all taxa. Although sexual swelling is found only in species with multi-male societies (Clutton-Brock \& Harvey, 1976), social systems vary among those species. It seems likely, therefore, that benefits of sexual swelling for females also differ between species and should be considered in the context of the social system in which they occur.

Bonobos (Pan paniscus) provide a unique opportunity for examining the function of sexual swelling as they have very prolonged periods of maximal swelling (Thompson-Handler et al., 1984; Furuichi, 1987; Dahl et al., 1991; Kano, 1992) and also females that achieve high social status in a male philopatric society (Furuichi, 1997, 2011; Surbeck et al., 2011). In many primate species sexual swelling reaches its maximal size near ovulation (Wildt et al., 1977; Dahl et al., 1991; Emery \& Whitten, 2003; Young et al., 2013) and affects male behaviours related to mating, such as consortship (Tokuda, 1961; Hall \& de Vore, 1965; Hill, 1987) or coercive mate guarding (Smuts \& Smuts, 1993; Muller et al., 2007). However, bonobos seem to deviate from this general trend, since the timing of their ovulation and onset of maximal swelling are highly variable (Furuichi, 1987; Heistermann et al., 1996; van Schaik et al., 2000; Reichert et al., 2002, but also see Surbeck et al., 2011) even compared with those of chimpanzees (Deschner et al., 2003). The high level of variation of timing of ovulation and onset of maximal swelling in this species seem to reflect effects of very prolonged periods of maximal swelling (Furuichi, 1987) of female bonobos. Therefore the key to understanding sexual swelling in bonobos may be found in the prolonged period of maximal swelling, which sometimes continues for more than 20 days (Furuichi, 1987; Ryu, unpublished data). 
Most previous research on the prolonged period of maximal swelling in bonobos has focused on its role in controlling the behaviour of males, by making females attractive to males even outside the oestrous periods (Furuichi, 1987, 2011; Kano, 1992; de Waal, 1995). This manipulative function of sexual swelling has been noted with the fact that there is no known case of coercive mate guarding and infanticide by males in bonobos (Furuichi \& Hashimoto, 2004; Paoli, 2009). It is, therefore, recognized as a successful female counter-strategy toward male mating strategy. However, without considering that female-female and female-male bonding play an important social role and that sexual swelling seems to have an important role in social bonding (Parish, 1994; Furuichi, 2011) in this male philopatric species, it will be impossible for us to reach a comprehensive understanding of the role and evolution of sexual swelling. Therefore it is important to take, not only mating-related function, but also function for social bonding into account for better understanding. This will provide a new direction and another important dimension for future studies. Some researchers have already mentioned other possible functions of this prolonged sexual swelling, such as maximal sexual swelling for genito-genital rubbing (hereafter g-g rubbing; Kuroda, 1980) rather than copulations (Takahata et al., 1996), or providing protection against male coercion by attracting other females rather than males (Paoli et al., 2006; Paoli, 2009), but these have not been considered thoroughly, or examined quantitatively. Considering the finding that g-g rubbing increases for females with maximal swelling (Kano, 1992; Hohmann \& Fruth, 2000, but also see Takahata et al., 1996), it is reasonable to assume that sexual swelling influences female-female social relationships in bonobos (Kano, 1992; Takahata et al., 1996; Paoli et al., 2006). In bonobos, new immigrant females, which are likely to have no stable social relationship with others in the group, are eager to interact with senior females (Furuichi, 1989; Idani, 1991), and such new immigrant females show very long-lasting maximal swelling (Furuichi, 1987). Therefore, if females can gain benefits from having maximal swellings in terms of their social interactions with other females, those benefits are likely to vary in relation to their life-history stage.

Based on these characteristics, we hypothesized that one function of prolonged sexual swelling in bonobos is to increase attractiveness to other females and facilitate social interaction with them (Swelling for female attraction). This hypothesis leads to the following predictions: 
1. Females with maximal swelling will be invited and/or engage in g-g rubbing more frequently than females without maximal swelling.

2. Females with maximal swelling will have more females in close proximity to them than females without maximal swelling.

3. Females with maximal swelling will spend more time in grooming interactions with other females than females without maximal swelling.

4. Young females with maximal swelling will receive more reciprocated grooming in interactions with other females.

To test this hypothesis and its predictions, we first investigated frequency of g-g rubbing as well as copulation in relation to age and swelling status. Second, we compared the number of females found within $1 \mathrm{~m}$ or $5 \mathrm{~m}$ of the focal animal, and those found in the same party. Finally, we investigated the frequency and reciprocity of grooming interactions in relation to age and swelling status of females.

\section{Materials and methods}

\subsection{Study site and subjects}

Data were collected at the long-term bonobo field site at Wamba in the northern sector of the Luo Scientific Reserve, D.R. Congo (Kano, 1992; Furuichi et al., 2012). The research camp is situated in the center of the northern section of the reserve $\left(0^{\circ} 11^{\prime} 07.6^{\prime \prime} \mathrm{N}, 22^{\circ} 37^{\prime} 57.5^{\prime \prime} \mathrm{E}\right.$; WGS84). One fully habituated unit-group (or community) of free-ranging wild bonobos, called E1 group, was followed. From 1974 to 1996 researchers conducted field research using provisioning. Field research was stopped in 1996 by the civil war. Since researchers resumed field research in 2003, no artificial food has been provided. E1 group ranges over primary, old and young secondary, and swamp forests and sometimes agricultural fields (Mulavwa et al., 2010). January and February have less rain (Mulavwa et al., 2008), although there is no clear division of dry season and rainy season.

The E1 group consisted of 28 to 31 individuals, including 7 adult and 3 adolescent males and 9 adult and 2 adolescent females during the study periods. Nine adult females, whose estimated ages ranged from 14 to 41 years old in 2012, were the targets of focal sampling (Altmann, 1974). All of them had immigrated into the E1 group and had successfully given birth at 
least once after their immigration. Among the 9 adult females, 2 females who were more than 38 years old (Table 1) were classified as old, and 4 females from 21 to 29 years old were classified as middle-aged. Three females of less than 20 years old were classified as young. All of the young adult females had just one record of successful parturition in the E1 group after their immigration and had an infant during the study periods. One of 2 adolescent females ( $\mathrm{Nc}$ ) was the daughter of the oldest female (No) and the other ( $\mathrm{Zn}$ ) immigrated in October 2011, and they were not included in focal sampling. $\mathrm{Hs}$ and Sl were already members of the E1 group at the time that field study was resumed in 2003, therefore their immigration was earlier than August 2003. Yk and Jk joined the E1 group in 2004 with infants, which was considered a possible example of group fusion (for more details, see Hashimoto et al., 2008).

\subsection{Assessment of sexual skin swelling}

Sexual swelling was scored on a daily basis in relation to firmness and size of each individual (Furuichi, 1987). Based on these records, the sexual swelling status of females was assigned to one of three categories: non-swelling (sw1), intermediate swelling (sw2) and maximal swelling (sw3). Firmness of sexual swelling was the key feature used to distinguish sw3 from sw2 since the size of swelling between 2 and 3, especially of young females, was not very different. Moreover because of great individual variation in swelling size, it has been suggested that firmness is a more reliable measure of sexual swelling in bonobo than size (Furuichi, 1987). To avoid observation errors and individual bias in the assessment of sexual skin swelling, at least one researcher and two research assistants discussed the swelling status of each female during field observations and during daily meetings in the evening. Sexual swelling of one female ( $\mathrm{Sl}$ ) did not reach sw3 during the study periods. This might reflect its pregnancy and postnatal infertility since it gave birth in December 2012 and was nursing its infant until the end of the second study period.

\subsection{Behavioural observation}

Data were collected by the first author from September 2011 to January 2012, and June to September 2012. During the study period, bonobos were followed for $1004.6 \mathrm{~h}$ on 134 days $(7.57 \pm 2.46 \mathrm{~h}$ per day). Bonobos were followed from their night beds, located before $06: 00 \mathrm{~h}$, until they made new 
Prolonged sexual swelling of female bonobos

291 [45]

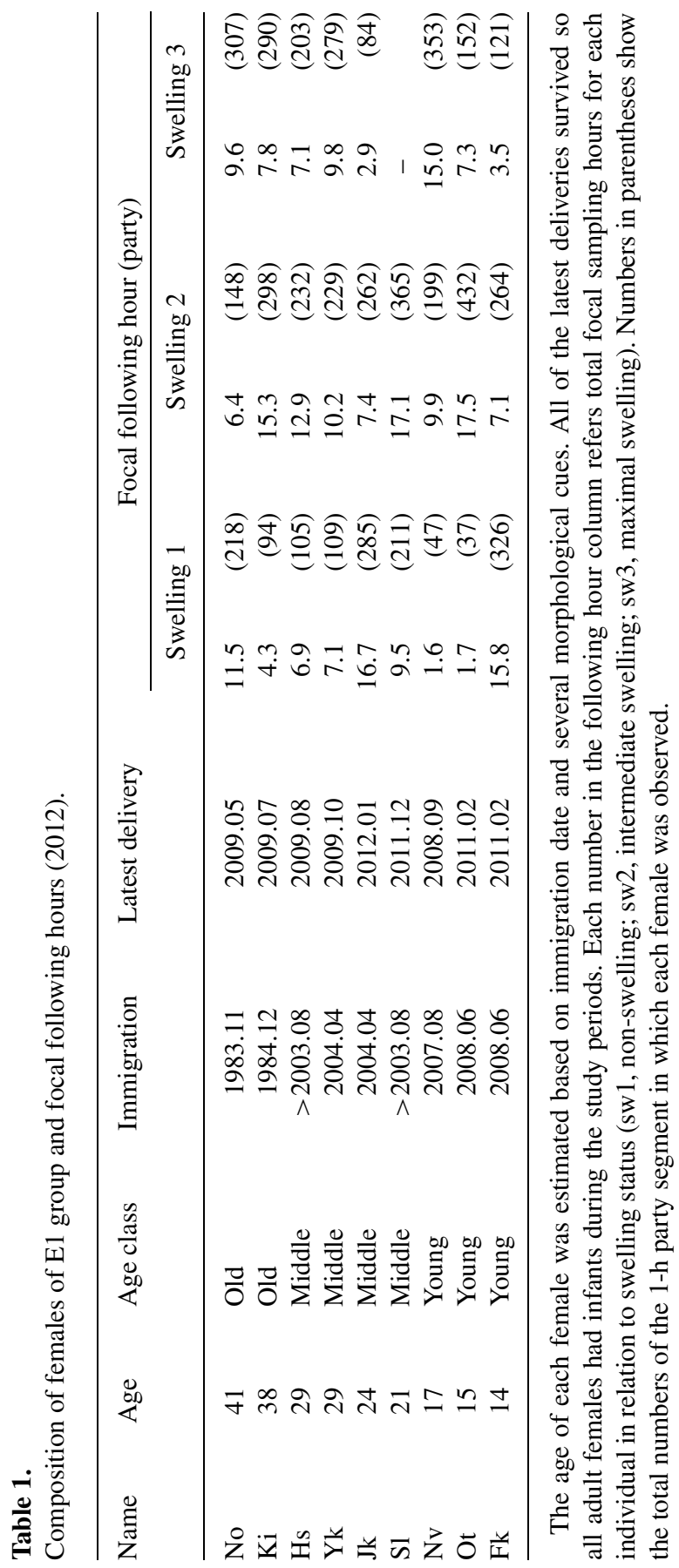


night beds, usually later than 17:00 h, by one or two researchers and at least two research assistants (one mainly followed the main party and the other usually helped researchers). Bonobos live in fission-fusion social systems (Kuroda, 1979; Kano, 1982; White, 1988), in which the composition of the membership of a party changes continuously (Aureli et al., 2008). When they split into several parties during daily ranging, the largest party was followed as far as possible. Party composition was recorded every single hour during party following (the 1-h party method; Hashimoto et al., 2001).

While bonobos were followed, one of the females in the party was randomly selected for continuous focal sampling. A random order for focal sampling for each day was generated before the beginning of daily observation. After bonobos were located in the morning at their bed site, HR and one research assistant looked for the first animal in the random sampling order for at least $30 \mathrm{~min}$. If we could not find the first one, we moved to the next one in the order, and so on. Some females had priority for focal animal selection because of a shortage of focal sampling data for them which was mainly due to the fission-fusion social system (sometimes some females were not observed for more than a week). One focal session was continued for $20 \mathrm{~min}$ and if a focal animal could not be located for more than 5 min within a focal session, the focal sampling was terminated. To keep a degree of independence of focal sampling of the same individual, focal follows for the same individual were separated by at least $100 \mathrm{~min}$. Within a focal session, all activities (e.g., feeding, moving, resting, grooming, agonistic interactions) involving the focal animal were recorded. All rare events, such as agonistic interactions (e.g., bite, hit, push and chase), copulations (Hashimoto, 1997) and g-g rubbing (Kuroda, 1980), which were observed during focal animals and parties following, were recorded. At the beginning of a focal session and every 5 min within the session (in total 5 scan points in a focal session), the names of neighbouring individuals within $5 \mathrm{~m}$ of the focal animal and their behaviours were recorded. The total focal following time for all individuals was $241.99 \mathrm{~h}$ (744 focal sessions; $26.89 \pm 0.39 \mathrm{~h}$ per individual) during $1004.3 \mathrm{~h}$ of party following on 134 days $(7.57 \pm 2.46 \mathrm{~h})$. The average length of a focal session was $19.5 \pm 1.1 \mathrm{~min}$ and each focal session consisted of $4.83 \pm 0.42$ scans (3591 scans in 744 focal sessions). More details for observed hours of each individual in relation to swelling status are shown in Table 1. 


\subsection{Data analysis}

All analyses were done using R 2.15.2 (R Core Team, 2012) in R-studio 0.97.248 (RStudio, 2012) with the following packages: lme4 (Douglas et al., 2012), glmmADMB (Sakug et al., 2012), nlme (Pinheiro et al., 2012), lmtest (Zeileis \& Hothorn, 2002), plyr (Wickham, 2002), fitdistrplus (DelignetteMuller et al., 2012), ggplot2 (Wickham, 2009). We used generalized linear mixed models (GLMM) or linear mixed models (LMM) to control for random effects of individual differences in the models. All models included swelling status (3 levels; non-swelling, intermediate swelling, maximal swelling) and age classes (3 levels; old, middle, young) as predictor variables. Interactions between swelling status and age classes were also examined in the models by visual inspection rather than by numerical inspection with data explorations, to avoid too many variables in the model.

\subsection{Analysis of copulation and genito-genital rubbing ( $g-g$ rubbing)}

To compare the frequency of copulation and g-g rubbing of females in relation to sexual swelling status, we used a generalized linear mixed model with negative binomial distribution (GLMM; Zuur et al., 2009). To examine the effects of swelling status and age on frequency of copulation and g-g rubbing (response variables), we included swelling status (3 levels: sw1-3) and age class ( 3 levels: young, middle, old) as predictor variables and ID of individuals as random variables in the model. Repeated copulations within the same dyad within $5 \mathrm{~min}$ (without any interruptions by others or copulation with others between repeated copulation) were considered to be one event. The number of copulations and $\mathrm{g}$-g rubbing interactions on each day for each female were response variables. Most of copulations and g-g rubbings which occurred within an observed party were detected by researchers and research assistants. However, because of the fission-fusion social system, daily observed time for each individual was different from each other. To control for the difference of observation time among individuals, we included the number of 1-h parties in which each female was observed in a day as an offset term in the model.

\subsection{Analysis of neighbouring female pattern}

To examine whether a female with maximal swelling attracted more females than females with other swelling status (non-swelling or intermediate swelling), the number of females in proximity to the focal females was 
analysed using GLMM with negative binomial distribution. Two separate GLMMs were conducted, including the number of females within $1 \mathrm{~m}$ and $5 \mathrm{~m}$ respectively in response variables, with swelling status and age classes as predictor variables. Because one focal session consisted of several scan points ( $4.83 \pm 0.42$ scan points), each scan point could be related to others to some degree. To control for this spatio-temporal autocorrelation, each scan in a focal session was nested in a focal session and the IDs of focal individuals were included as random variables in the model. Because it was also possible that spatio-temporal distribution of females in a 1-h party could have some effect on the neighbouring females, the number of females in a 1-h party (response variable) in relation to swelling status and age class (predictor variable) were also examined by running another GLMM.

\subsection{Analysis of grooming interactions}

Because bonobos almost exclusively engaged in dyadic grooming interactions and very rarely in mutual grooming interactions (Sakamaki, 2013), we analysed only dyadic grooming interactions without mutual grooming (mutual grooming was observed only once in one dyad for $40 \mathrm{~s}$ in this study). To examine the effect of sexual swelling and age on the grooming interactions of females (which might reflect sociality of females), first, we examined occurrence of grooming in each focal session (response variable 0 or 1) in relation to swelling status and age class (predictor variables) by running a GLMM. Second, we compared the grooming reciprocity index (response variable) only in the focal sessions in which grooming interaction was observed using a linear mixed model (LMM), to examine the effect of sexual swelling and age class (predictor variables) on grooming reciprocity. In these two-step analyses, individual differences were controlled by including them as a random effect of the model. The grooming reciprocity index was calculated as follows:

$$
\mathrm{R}(\mathrm{A})=\mathrm{Ge}(\mathrm{B})-\mathrm{Gr}(\mathrm{A}) / \mathrm{Ge}(\mathrm{B})+\mathrm{Gr}(\mathrm{A})
$$

$R(A)$ : Grooming reciprocity index of $A$, while $A$ was a focal animal (grooming with B)

$$
\begin{aligned}
& \operatorname{Gr}(A): \sum \text { (A groomed B, while A was a focal animal) } \\
& \operatorname{Ge}(B): \sum \text { (A groomed by B, while A was a focal animal) }
\end{aligned}
$$

The value of the grooming reciprocity index: $R(A)$ ranges from -1 (which means that A groomed B, but A was not groomed by B at all during the focal 
session) to 1 (which means that $\mathrm{A}$ was groomed by $\mathrm{B}$, although $\mathrm{A}$ did not groom $B$ at all).

\section{Results}

\subsection{Copulation in relation to swelling status and age}

In total 275 copulations were observed involving 9 adult females and 10 adult and adolescent males. These comprised 208 copulation events, when copulations that were repeated within 5 min were counted as one event. Females with maximal sexual swelling had more copulations than females with any other sexual swelling status (Figure 1a; for more details of GLMM, see Table 2). Young females also had more copulations than middle-aged or old females (Figure 1a; for more details of GLMM, see Table 2). The two old females did not copulate outside of their maximal swelling periods.

\section{2. $G$ - $g$ rubbing and solicitation of $g-g$ rubbing in relation to swelling status and age}

184 cases of g-g rubbing were observed involving the 9 adult females. Females with maximal sexual swelling engaged in $\mathrm{g}$-g rubbing more frequently than females with non-maximal swelling (Figure 1b; for more details of GLMM, see Table 2). There was no relationship between frequency of g-g rubbing and age. G-g rubbing typically in feeding contexts, such as immediately after entering a fruiting tree, or after encountering a food item $(89.8 \%$; 141 out of $157 \mathrm{~g}$-g rubbing interactions in which context could be clearly confirmed). Because solicitation or initiation of g-g rubbing was confirmed in only 54 cases out of 184 (29.3\%), we did not conduct statistical analysis for solicitation of the interaction. However, females with maximal swelling solicited other females with maximal swelling most frequently; in 25 of 54 g-g rubbings $(44.64 \%)$. The second most frequently observed solicitation was between females with intermediate sexual swelling (16.07\%), and the third most frequently observed one was females with intermediate sexual swelling soliciting females with maximal swelling (14.29\%). Solicitation between other combinations of females was less than $10 \%$ for each.

\subsection{Females in the proximity and in the same party}

Focal females had other females within $1 \mathrm{~m}$ (including females in contact with the focal females) in $17.3 \%$ of scans (621 of 3591), and the mean 


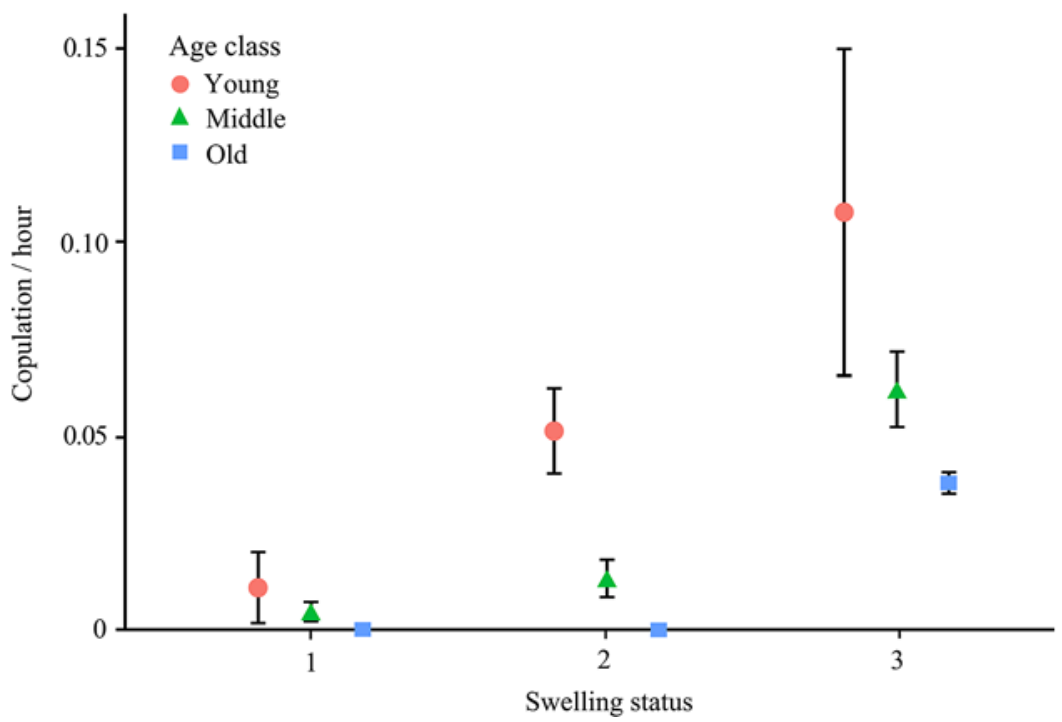

(a)

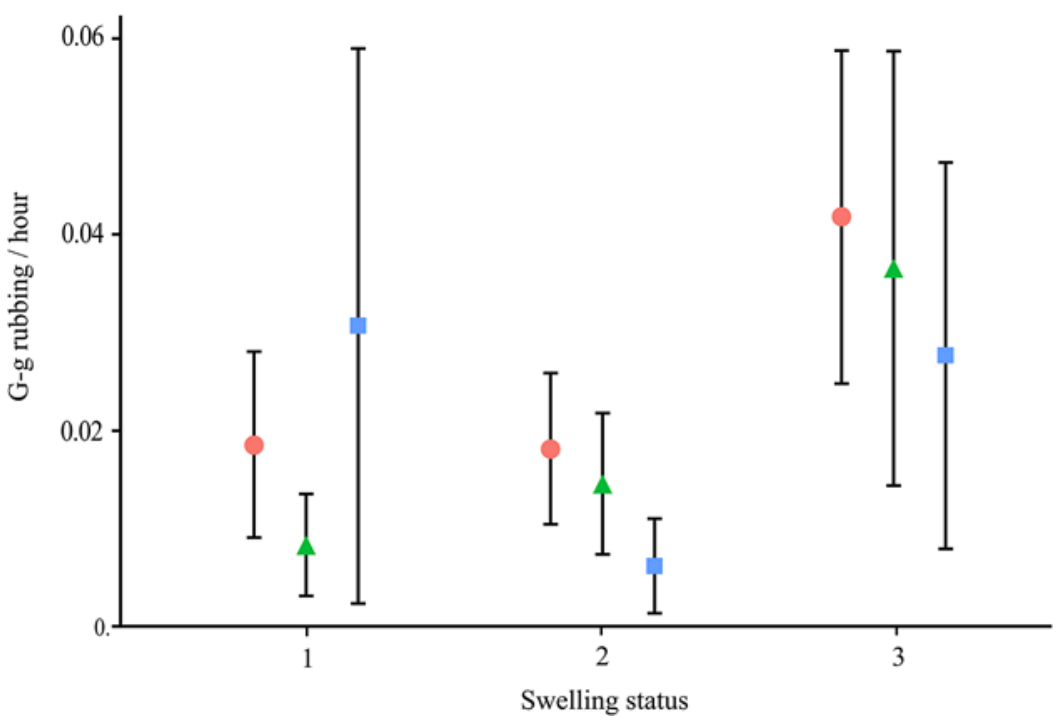

(b)

Figure 1. Mean number of copulations and g-g rubbing interactions per hour with standard error. (a) Copulations in relation to swelling status and age. (b) G-g rubbing interactions in relation to swelling status and age. This figure is published in colour in the online edition of this journal, which can be accessed via http://booksandjournals.brillonline.com/content/ journals/1568539x. 


\section{Table 2.}

Negative binomial GLMM results of copulation and genito-genital rubbing in relation to swelling status and age.

\begin{tabular}{|c|c|c|c|c|c|c|c|c|}
\hline \multirow[t]{2}{*}{ Predictor variable } & \multicolumn{4}{|c|}{ Copulation } & \multicolumn{4}{|c|}{ g-g rubbing } \\
\hline & Estimate & SE & $Z$ & $p(>|Z|)$ & Estimate & SE & $Z$ & $p(>|Z|)$ \\
\hline Intercept & -5.380 & 0.416 & -12.94 & $<0.001$ & -5.782 & 0.540 & -10.71 & $<0.001$ \\
\hline Swelling 1 vs. 3 & -4.311 & 0.536 & -8.04 & $<0.001^{*}$ & -1.629 & 0.387 & -4.21 & $<0.001^{*}$ \\
\hline Swelling 2 vs. 3 & -2.357 & 0.383 & -6.15 & $<0.001^{*}$ & -1.403 & 0.334 & -4.20 & $<0.001^{*}$ \\
\hline $\begin{array}{l}\text { Middle-aged } \\
\text { vs. Young }\end{array}$ & -1.159 & 0.492 & -2.35 & $0.019^{*}$ & -0.185 & 0.677 & -0.27 & 0.79 \\
\hline Old vs. Young & -3.259 & 0.625 & -5.21 & $<0.001^{*}$ & -0.830 & 0.807 & -1.03 & 0.30 \\
\hline
\end{tabular}

number of females within $1 \mathrm{~m}$ was $0.21 \pm 0.51$ (Figure 2a). Focal females had other females within $5 \mathrm{~m}$ in $40.8 \%$ of scans (1465 of 3591), and the mean number of females within $5 \mathrm{~m}$ was $0.63 \pm 0.93$ (Figure 2b). Focal females had $3.39 \pm 2.23$ female companions within the same 1-h party (Figure 2c). Females with maximal sexual swelling had more females within $1 \mathrm{~m}$ than those of other swelling status (GLMM; Table 3). Females with maximal swelling did not have females within $5 \mathrm{~m}$ compared with nonswelling females, although there was a significant difference compared with females with intermediate swelling (GLMM; Table 3). Females with maximal swelling, joined larger parties which consisted of more females than non-swelling females (Table 3), but there was no significant difference compared with females with intermediate swelling (Table 3).

\subsection{Grooming frequency}

Grooming interactions involving the focal animal were observed in $14.9 \%$ of focal sessions (111 focal sessions of 744). Females spent $8.69 \%$ of all focal animal following time (20.99 focal following hours of 241.99) in grooming interaction (sw1: $7.71 \% ; 5.79 \mathrm{~h}, \mathrm{sw} 2: 6.93 \% ; 7.17 \mathrm{~h}$, sw3: 12.74\%; $8.04 \mathrm{~h}$, respectively). Comparison of the number of focal sessions (only in which grooming interaction was observed) in relation to swelling status showed that females with maximal swelling engaged in grooming interactions more often than females of other swelling status (non-swelling: 12.6\% (29 focal sessions of 230), intermediate swelling: $12.8 \%$ (41 focal sessions of 320), maximal swelling: $21.1 \%$ (41 focal sessions of 194); Figure 3a, GLMM; 


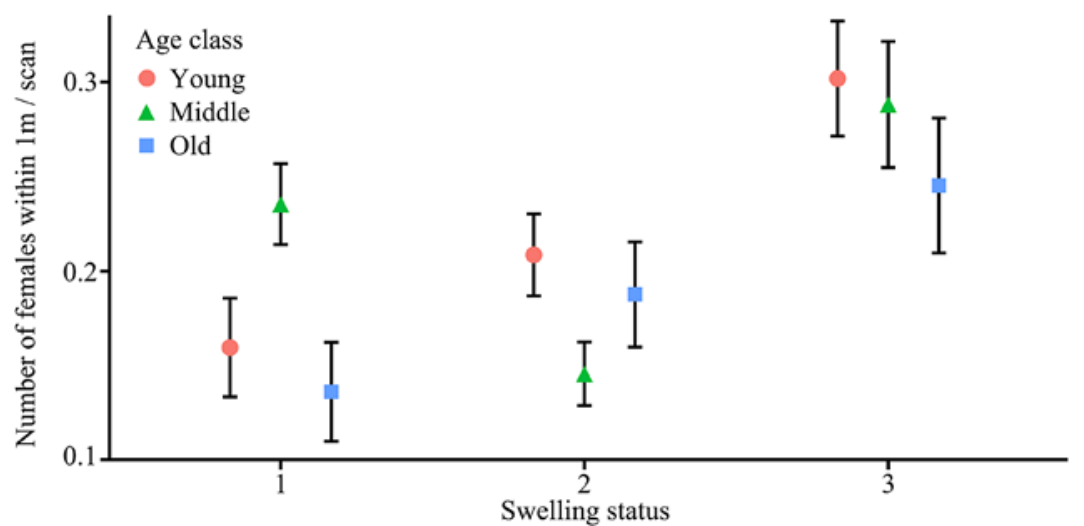

(a)

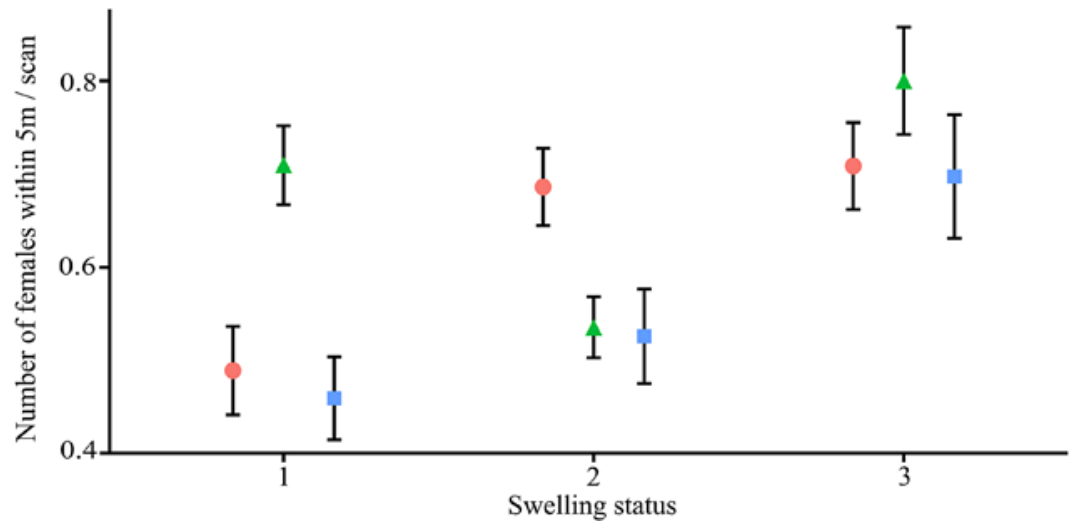

(b)

Figure 2. Mean number of females within $1 \mathrm{~m}, 5 \mathrm{~m}$ and party. (a) Number of females within $1 \mathrm{~m}$ in relation to swelling status and age. (b) Number of females within $5 \mathrm{~m}$ in relation to swelling status and age. (c) Number of females in 1-h party in relation to swelling status and age. This figure is published in colour in the online edition of this journal, which can be accessed via http://booksandjournals.brillonline.com/content/journals/1568539x.

Table 4). Young females engaged in grooming interactions more often than old females, but not more than middle-aged females (GLMM; Table 4).

\subsection{Grooming reciprocity}

The grooming reciprocity index was calculated independently for 111 focal sessions. Although old and middle-aged females seemed to have a higher overall reciprocity index (old: 0.275 , middle: 0.078 , young: -0.332 ) which might imply that they received more grooming than young females, this 


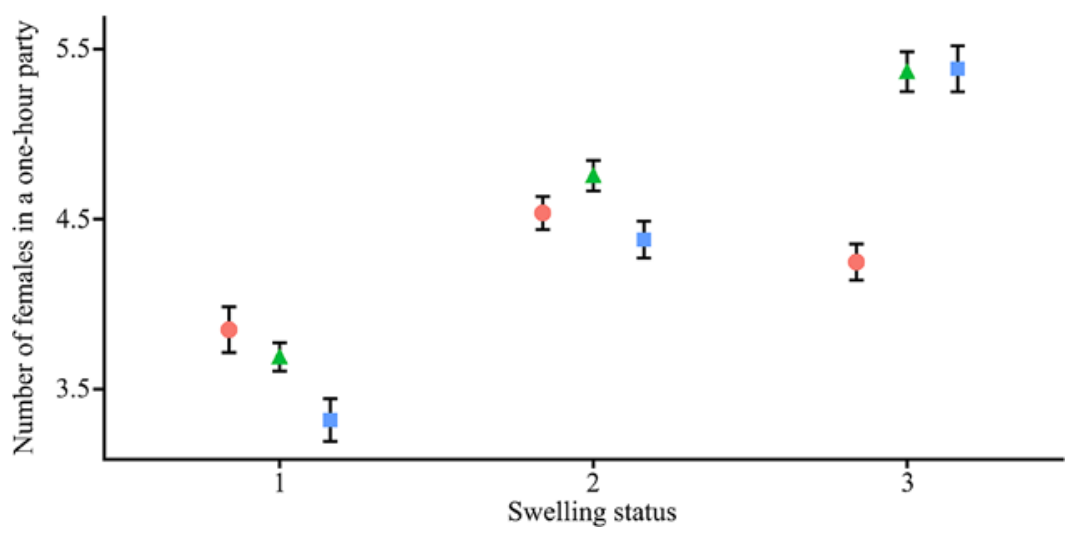

(c)

Figure 2. (Continued.)

difference was not statistically significant (Figure 3b, LMM; Table 4). Females with maximal swelling had significant higher reciprocity index scores than those of intermediate swelling status (LMM; Table 4), but no difference was found compared with non-swelling status (LMM; Table 4). Although increase of reciprocity index of young females according to swelling sta-

\section{Table 3.}

Negative binomial GLMM results of number of females within $1 \mathrm{~m}$, within $5 \mathrm{~m}$ and within 1-h party in relation to swelling status and age.

\begin{tabular}{|c|c|c|c|c|c|c|}
\hline & GLMM & Intercept & $\begin{array}{l}\text { Swelling } 1 \\
\text { vs. } 3\end{array}$ & $\begin{array}{l}\text { Swelling } 2 \\
\text { vs. } 3\end{array}$ & $\begin{array}{l}\text { Middle-aged } \\
\text { vs. Young }\end{array}$ & $\begin{array}{c}\text { Old } \\
\text { vs. Young }\end{array}$ \\
\hline \multirow[t]{4}{*}{ Within $1 \mathrm{~m}$} & Estimate & -2.517 & -0.613 & -0.788 & -0.069 & -0.349 \\
\hline & $\mathrm{SE}$ & 0.240 & 0.257 & 0.239 & 0.224 & 0.267 \\
\hline & $Z$ & -10.480 & -2.390 & -3.300 & -0.310 & -1.310 \\
\hline & $p(>|Z|)$ & $<0.001$ & $0.017^{*}$ & $0.001^{*}$ & 0.756 & 0.192 \\
\hline \multirow[t]{4}{*}{ Within $5 \mathrm{~m}$} & Estimate & -0.933 & -0.174 & -0.307 & -0.030 & -0.196 \\
\hline & $\mathrm{SE}$ & 0.180 & 0.166 & 0.142 & 0.205 & 0.244 \\
\hline & $Z$ & -5.180 & -1.050 & -2.160 & -0.150 & -0.800 \\
\hline & $p(>|Z|)$ & $<0.001$ & 0.295 & $0.031^{*}$ & 0.883 & 0.422 \\
\hline \multirow[t]{4}{*}{ Within party } & Estimate & 1.471 & -0.350 & -0.091 & -0.082 & -0.038 \\
\hline & SE & 0.046 & 0.053 & 0.049 & 0.046 & 0.054 \\
\hline & $Z$ & 31.930 & -6.560 & -1.860 & 1.790 & 0.710 \\
\hline & $p(>|Z|)$ & $<0.001$ & $<0.001^{*}$ & 0.063 & 0.073 & 0.473 \\
\hline
\end{tabular}

* Significant difference $(p<0.05)$. 


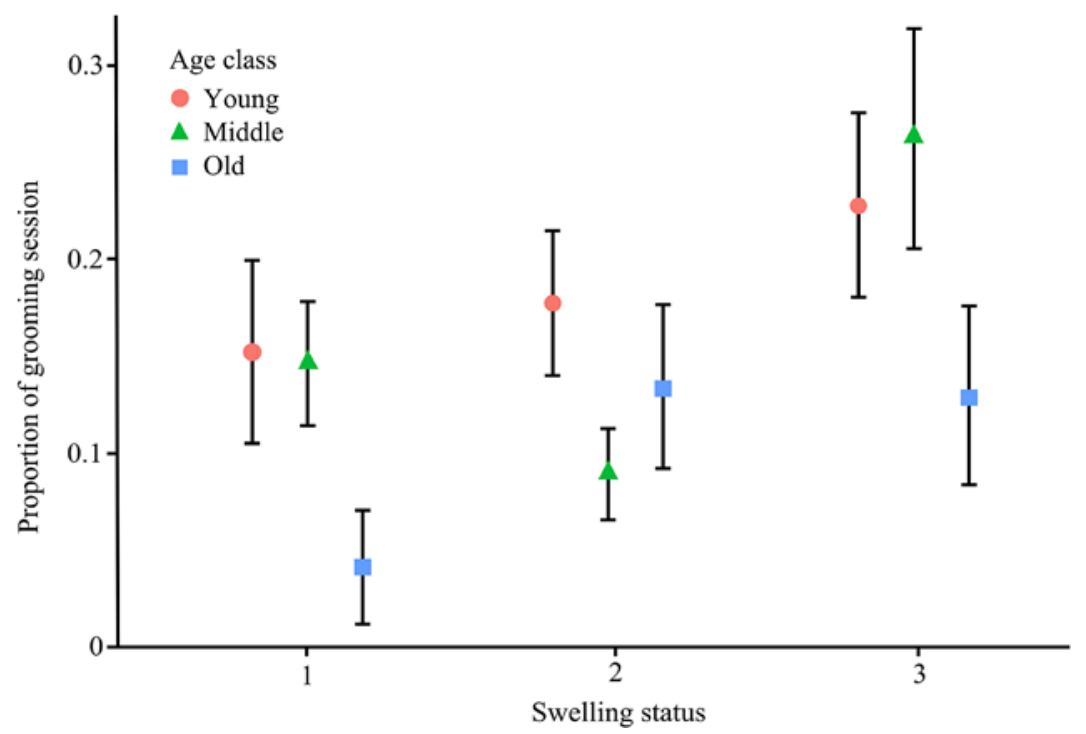

(a)

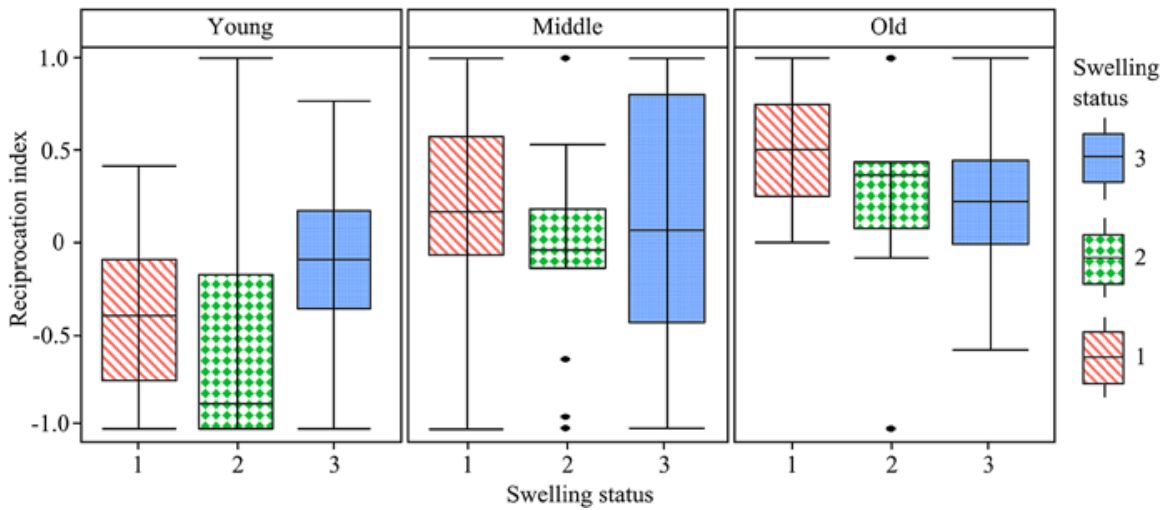

(b)

Figure 3. Grooming frequency and reciprocity. (a) Proportion of focal sessions in which grooming interaction was observed. (b) Grooming reciprocity index. Each box indicates upper quartile and lower quartile and dots indicate outliers. This figure is published in colour in the online edition of this journal, which can be accessed via http://booksandjournals. brillonline.com/content/journals/1568539x.

tus appeared to be different from the tendencies found in the other two age classes (Figure 3b), interaction between the two predictor variables (age class and swelling) was not statistically significant. However, further analysis with linear mixed model (LMM) on each age category revealed that there was no 


\section{Table 4.}

Binomial GLMM results of comparison of the number of focal sessions which included grooming interactions and linear mixed model (LMM) result of comparison of grooming reciprocity index in relation to swelling and age.

\begin{tabular}{|c|c|c|c|c|c|c|c|c|}
\hline \multirow[t]{2}{*}{ Predictor variable } & \multicolumn{4}{|c|}{ Focal session with grooming } & \multicolumn{4}{|c|}{ Grooming reciprocity index } \\
\hline & Estimate & SE & $Z$ & $p(>|Z|)$ & Estimate & SE & $T$ & $p(>|Z|)$ \\
\hline Intercept & -1.076 & 0.211 & -5.10 & $<0.001$ & -0.205 & 0.174 & -1.182 & 0.240 \\
\hline Swelling 1 vs. 3 & -0.610 & 0.271 & -2.26 & $0.024^{*}$ & -0.072 & 0.147 & -0.487 & 0.628 \\
\hline Swelling 2 vs. 3 & -0.612 & 0.246 & -2.49 & $0.013^{*}$ & -0.259 & 0.124 & -2.077 & $0.040^{*}$ \\
\hline $\begin{array}{l}\text { Middle-aged } \\
\text { vs. Young }\end{array}$ & -0.242 & 0.232 & -1.04 & 0.296 & 0.340 & 0.221 & 1.541 & 0.174 \\
\hline Old vs. Young & -0.668 & 0.300 & -2.23 & $0.026^{*}$ & 0.630 & 0.266 & 2.372 & 0.055 \\
\hline
\end{tabular}

* Significant difference $(p<0.05)$.

difference in grooming reciprocity index in middle-aged and old females in relation to sexual swelling, but there was a significant difference among swelling phases in young females. The pairwise test with LMM showed that the reciprocity index in young females was significantly higher in maximal swelling than in intermediate swelling $(p=0.013, t=-2.599, \mathrm{SE}=0.184)$, though the difference between maximal swelling and non-swelling was a non-significant tendency ( $p=0.097, t=-1.695, \mathrm{SE}=0.098)$.

\section{Discussion}

Female bonobos are highly social (Furuichi, 1987; White, 1988; Kano, 1992; Hohmann et al., 1999) and more central in their society than female chimpanzees (Furuichi, 1989; Kano, 1992; Parish, 1994; Furuichi, 2011; Surbeck et al., 2011). Previous studies have suggested that prolonged sexual swelling of this species may contribute to the more female-centred society of bonobos by diminishing the competitive element of male mating strategy (Furuichi, 2011; Surbeck et al., 2011). Although this study also supported the idea that sexual swelling attracts males as a sexual signal, the four predictions concerning female-female interactions were also supported. Thus our results support the hypothesis that the prolonged sexual swellings of female bonobos also facilitate female-female interactions by making females with maximal swelling more attractive to other females. Therefore, this study suggests that prolonged sexual swelling might be a physiological adaptation in 
this species to maintain high level of affiliative social bonding among females and may contribute to high social status of females in the society (de Waal, 1995; Parish et al., 2000; Furuichi, 2011). In addition, the function of sexual swelling in bonobos and chimpanzees may differ in that sexual swelling in chimpanzees seems to function mainly to attract males (Boesch \& Boesch-Achermann, 2000; Hashimoto et al., 2001). It would be very useful to examine the extent of variation between populations or sub-species in chimpanzees and bonobos for a better understanding of the function of sexual swelling in Pan species.

\subsection{Increased socio-sexual behaviour during the maximal swelling period offemales}

Our data showed that the frequency of copulation was clearly related to the swelling status in all age classes, which is consistent with previous reports from wild populations (Furuichi, 1987; Surbeck et al., 2011). Although some captive studies have reported that females copulated with males throughout swelling cycles, with the exception of a few days (Savage-Rumbaugh \& Wilkerson, 1978; de Waal, 1995), this study showed that this tendency was prominent for young females only. Young females (less than 5 years of tenure) had higher copulation frequencies than other females even in nonmaximal swelling periods. By contrast, two old females never copulated with males outside of maximal swelling status. This result may indicate that the need for socio-sexual activity is greater for young females than old females, because they have relatively short tenure in the group and therefore, may be more vulnerable to competition even with males. On the other hand, it could be that they need male support in agonistic interactions with other females, which is predicted by the social passport hypothesis (Boesch \& Boesch-Achermann, 2000; Deschner \& Boesch, 2007).

Considering the fact that $\mathrm{g}$-g rubbing was most frequent in female dyads with maximal swelling and this interaction occurs most frequently in feeding contexts (89.8\% in this study, $79.5 \%$ in Hohmann \& Fruth, 2000), females with maximal swelling can take advantage of their condition in feeding contexts. In particular, young females, whose rank is usually low (Furuichi, 1997; Ryu, unpublished data) and are, therefore, at a disadvantage in feeding competition, can gain more benefits from keeping maximal swelling since genito-genital rubbing requires body contact and therefore decreases distance and may also reduce tension between two participants (Furuichi, 1989; 
Hohmann \& Fruth, 2000). This may also explain the benefits and the function of very long-lasting maximal swelling of new immigrant females (Furuichi, $1987,1992)$ although they were not the subjects of this study.

\subsection{Increased social interaction and attractiveness of females with maximal swelling}

Females with maximal swelling tended to have more females in proximity, and this tendency was more significant in $1 \mathrm{~m}$ proximity, which corresponds to the 'personal distance' defined in the proxemics as established by Hall (1966). Females with maximal swelling also had more females in the same 1-h party, although the difference between intermediate swelling and maximal swelling was not significant. These results suggest that females with maximal swelling attended bigger parties, or that they attracted other females to attend parties, although it was not possible to distinguish between these two possibilities in this study.

It has been reported that time spent in proximity is highly correlated with frequency of affiliative social interaction in primates (rhesus macaques (Macaca mulatta) (Hill, 1987); baboon (Papio cynocephalus) (Silk et al., 2003); ring-tailed lemurs (Lemur catta) (Sbeglia et al., 2010)) and, thus, staying in very close proximity, such as within $1 \mathrm{~m}$, probably facilitates social interaction or at least indicates mutual or one-directional attraction among females. Therefore, together with grooming interaction and g-g rubbing data including solicitation of interaction, the increased number of females within $1 \mathrm{~m}$ of females with maximal swelling implies that females with maximal swelling were attractive for other females for social interaction.

This study also suggested that sexual swelling played a positive role in grooming interactions. The high frequency of grooming interactions of young females is also compatible with previous reports that young females had higher needs of social bonding with other females than older females (Furuichi, 1989; Idani, 1991). This implies that the benefits and reason to keep maximal swelling might vary in relation to female age. Although young females showed lower grooming reciprocity indices in general, it shifted to almost the same as old and middle-aged females when they had maximal swelling.

Newly-immigrated young female bonobos show very prolonged periods of maximal swelling (Furuichi, 1987, 1992) which were longer than adult females which are already settled in the group. In chimpanzees, it has been 
suggested that maximal swelling of new immigrant females is to attract males to facilitate the immigration process (Boesch \& Boesch-Achermann, 2000). However this study provides an additional scenario in which maximal swelling of new immigrant females in bonobos is also used to facilitate female-female social interaction as well as male attraction. Increasing the periods of maximal swelling may help new immigrant females to integrate into the new group more easily. If females with maximal swelling are more socially active and attract other females for social interactions with them, prolonged periods of maximal swelling are more beneficial for immigrant young females whose needs of social bonding with more senior females seem to be greater (Furuichi, 1989; Idani, 1991).

Grooming in primates has been studied intensively and has been shown to have important social functions in maintaining and strengthening social relationships (Seyfarth, 1977; McKenna, 1978; Hill, 1987; Spruijt et al., 1992), regulating stress and tension (Spruijt et al., 1992), and may also function as currency exchanged for tolerance or agonistic support (Henzi \& Barrett, 1999). Therefore, increased reciprocity in grooming interactions of young females with maximal swelling may result in direct benefits such as reducing stress, ecto-parasite load and facilitating social bonding. It may also help young females to strengthen social bonding with other females in the longterm. Such benefit seems to be greater for bonobos, in which senior females tend to have high social status and play central social roles (Parish, 1994, 1996; Furuichi, 2011).

Overall, this study suggests that one of the keys to understanding the function of sexual swelling in bonobos (especially for young females) is increased attractiveness of females for social interactions during prolonged maximal swelling periods. Female bonobos show prolonged periods of maximal swelling throughout their lifetimes (ca. $27 \%$ of time inter-birth interval within the average 4.8 years birth interval; Furuichi \& Hashimoto, 2002). However, it is not reasonable to assume that these prolonged periods of maximal swelling evolved only for male attraction, since female bonobos showed lower copulation rates than female chimpanzees (Furuichi \& Hashimoto, 2002) during maximal swelling periods and also females can be receptive even in non-maximal swelling cycles, as was found in young females in this study.

Therefore we suggest, in conclusion, that attraction of other females has become an additional function of sexual swelling in bonobos, which originally evolved as a sexual signal to males. In other words, prolonged periods 
of maximal swelling in bonobos may have evolved partly to facilitate social interaction among females and may contribute to a female-centred social structure by facilitating female-female bonding in a male-philopatric society (White, 1988; Parish, 1994; Furuichi, 2011; Surbeck et al., 2011). Together with the results of this study and previous suggestions that sexual swellings have disappeared and re-emerged at least three times during speciation (Nunn, 1999), the function of sexual swelling may differ among species. Therefore, we suggest that it is useful to consider the demography and socio-ecological factors of each species for a more comprehensive understanding of the function and evolution of sexual swelling in Old World monkeys and apes.

During the long life-span of bonobos, they encounter demographical and socio-environmental changes which have to be dealt with in order to live in the group and minimize fitness loss. Therefore it seems to be more advantageous for females if they have some degree of flexibility in the length of maximal swelling periods in relation to their life-history or socio-environmental or demographical changes since sexual swelling also incurs some costs. Although it has yet to be investigated thoroughly and quantitatively, there seems to be some degree of flexibility and individual difference in occurrence of maximal swelling (Furuichi, 1987; Furuichi, 1992). Long-term field study will clarify this speculation about the flexibility of keeping maximal swelling and will provide valuable perspectives on understanding female sexuality and its evolution, not only in this species, but also in humans.

\section{Acknowledgements}

We thank Dr. MacIntosh for his advice on statistical analysis. We also thank our research assistants at Wamba, especially Mr. Bafutsa, Mr. Bafaluka, Mr. Eteny, Mr. Batsindelia, Mr. Isoluka and Mr. Bafike, for their great help. Finally we thank the members of Department of Ecology and Social Behavior and CICASP at the Primate Research Institute of Kyoto University, in particular Dr. Bercovitch, Dr. Huffman, Dr. Sakamaki, Ms. Tokuyama, Dr. Tsuji and Sojung Han for comments and help. This study was supported by the Environment Research and Technology Development Fund (D-1007 to T.F.), Japan Society for the Promotion of Science (JSPS) Grants-in-aid for Scientific Research (22255007 to T.F.), the JSPS Asia-Africa Science Platform Program (2009-2011, 2012-2014 to T.F.), JSPS ITP-HOPE Project (ITP-23012 to H.R.) and JSPS AS-HOPE Project (AS-24-007 to H.R.). We thank the 
Ministry of Scientific and Technological Research of the D.R. Congo for research permissions (No MIN.RS/SG/013/2011, MIN.ESURS/SG/010/2012) and the Research Centre of Ecology and Forestry for helping us and maintaining Luo Scientific Reserve.

\section{References}

Alberts, S.C. \& Fitzpatrick, C.L. (2012). Paternal care and the evolution of exaggerated sexual swellings in primates. - Behav. Ecol. 23: 699-706.

Altmann, J. (1974). Observational study of behavior: sampling methods. - Behaviour 49: 227-267.

Anderson, C.M. \& Bielert, C.F. (1994). Adolescent exaggeration in female catarrhine primates. - Primates 35: 283-300.

Aureli, F., Schaffner, C.M., Boesch, C., Bearder, S.K., Call, J., Chapman, C.A., Connor, R., Fiore, A.D., Dunbar, R.I.M., Henzi, S.P., Holekamp, K., Korstjens, A.H., Layton, R., Lee, P., Lehmann, J., Manson, J.H., Ramos-Fernandez, G., Strier, K.B. \& van Schaik, C.P. (2008). Fission-fusion dynamics: new research frameworks. — Curr. Anthropol. 49: 627654.

Bercovitch, F.B. (1988). Coalitions, cooperation and reproductive tactics among adult male baboons. - Anim. Behav. 36: 1198-1209.

Bielert, C. \& Busse, C. (1983). Influences of ovarian hormones on the food intake and feeding of captive and wild female chacma baboons (Papio ursinus). — Physiol. Behav. 30: 103111.

Boesch, C. \& Boesch-Achermann, H. (2000). The chimpanzees of the Taï Forest: behavioural ecology and evolution. - Oxford University Press, New York, NY.

Clutton-Brock, T.H. \& Harvey, P.H. (1976). Evolutionary rules and primate societies. — In: Growing points in ethology (Bateson, P.P.G. \& Hinde, R.A., eds). Cambridge University Press, Cambridge, p. 195-237.

Dahl, J.F., Nadler, R.D. \& Collins, D.C. (1991). Monitoring the ovarian cycles of Pan troglodytes and P. paniscus: a comparative approach. - Am. J. Primatol. 24: 195-209.

de Waal, F.B.M. (1995). Bonobo sex and society. - Sci. Am. 272: 82-88.

Delignette-Muller, M.L., Pouillot, R., Denis, J.-B. \& Dutang, C. (2012). fitdistrplus: help to fit of a parametric distribution to non-censored or censored data. $-\mathrm{R}$ package version $1.0-0$.

Deschner, T. \& Boesch, C. (2007). Can the patterns of sexual swelling cycles in female Taï chimpanzees be explained by the cost-of-sexual-attraction hypothesis? - Int. J. Primatol. 28: 389-406.

Deschner, T., Heistermann, M., Hodges, K. \& Boesch, C. (2003). Timing and probability of ovulation in relation to sex skin swelling in wild West African chimpanzees, Pan troglodytes verus. - Anim. Behav. 66: 551-560.

Dixson, A.F. (1977). Observations on the displays, menstrual cycles and sexual behaviour of the "Black ape" of Celebes (Macaca nigra). — J. Zool. 182: 63-84. 
Dixson, A.F. (1983). Observations on the evolution and behavioral significance of "sexual skin" in female primates. - Adv. Stud. Behav. 13: 63-106.

Douglas, B., Martin, M. \& Ben, B. (2012). lme4: linear mixed-effects models using S4 classes. - RStudio, Boston, MA.

Emery, M.A. \& Whitten, P.L. (2003). Size of sexual swellings reflects ovarian function in chimpanzees (Pan troglodytes). — Behav. Ecol. Sociobiol. 54: 340-351.

Furuichi, T. (1987). Sexual swelling, receptivity, and grouping of wild pygmy chimpanzee females at Wamba, Zaire. - Primates 28: 309-318.

Furuichi, T. (1989). Social interactions and the life history of female Pan paniscus in Wamba, Zaire. - Int. J. Primatol. 10: 173-197.

Furuichi, T. (1992). The prolonged estrus of females and factors influencing mating in a wild group of bonobos (Pan paniscus) in Wamba, Zaire. - In: Topics in primatology 2. Behavior, ecology, and conservation (Itoigawa, N., Sugiyama, Y., Sackett, G.P. \& Thompson, R.K.R., eds). University of Tokyo Press, Tokyo, p. 179-190.

Furuichi, T. (1997). Agonistic interactions and matrifocal dominance rank of wild bonobos (Pan paniscus) at Wamba. — Int. J. Primatol. 18: 855-875.

Furuichi, T. (2011). Female contributions to the peaceful nature of bonobo society. - Evol. Anthropol. Issues News Rev. 20: 131-142.

Furuichi, T. \& Hashimoto, C. (2002). Why female bonobos have a lower copulation rate during oestrus than chimpanzees. - In: Behavioural diversity in chimpanzees and bonobos (Boesch, C., Hohmann, G. \& Marchant, L.F., eds). Cambridge University Press, Cambridge, p. 156-167.

Furuichi, T. \& Hashimoto, C. (2004). Sex differences in copulation attempts in wild bonobos at Wamba. - Primates 45: 59-62.

Furuichi, T., Idani, G., Ihobe, H., Hashimoto, C., Tashiro, Y., Sakamaki, T., Mulavwa, M.N., Yangozene, K. \& Kuroda, S. (2012). Long-term studies on wild bonobos at Wamba, Luo Scientific Reserve, D. R. Congo: towards the understanding of female life history in a male-philopatric species. — In: Long-term field studies of primates (Kappeler, P.M. \& Watts, D.P., eds). Springer, Berlin, p. 413-433.

Hall, E.T. (1966). The hidden dimension. — Doubleday, New York, NY.

Hall, K.R.L. \& de Vore, I. (1965). Baboon social behavior. — In: Primate behavior: field studies of monkeys and apes (De Vore, I., ed.). Holt, Rinehart and Winston, New York, NY, p. 55-110.

Hamilton, W.J.I. (1984). Significance of paternal investment by primates to the evolution of adult male-female associations. - In: Primate paternalism (Taub, D.M., ed.). Van Nostrand Reinhold, New York, NY, p. 309-335.

Hashimoto, C. (1997). Context and development of sexual behavior of wild bonobos (Pan paniscus) at Wamba, Zaire. - Int. J. Primatol. 18: 1-21.

Hashimoto, C., Furuichi, T. \& Tashiro, Y. (2001). What factors affect the size of chimpanzee parties in the Kalinzu Forest, Uganda? Examination of fruit abundance and number of estrous females. - Int. J. Primatol. 22: 947-959.

Hashimoto, C., Tashiro, Y., Hibino, E., Mulavwa, M., Yangozene, K., Furuichi, T., Idani, G. \& Takenaka, O. (2008). Longitudinal structure of a unit-group of bonobos: male philopatry 
and possible fusion of unit-groups. - In: The bonobos: behavior, ecology, and conservation (Furuichi, T. \& Thompson, J., eds). Springer, New York, NY, p. 107-119.

Hausfater, G. (1975). Dominance and reproduction in baboons (Papio cynocephalus): a quantitative analysis. - In: Contributions to primatology. Karger, Basel, p. 1-150.

Heistermann, M., Möhle, U., Vervaecke, H., Van Elsacker, L. \& Hodges, J.K. (1996). Application of urinary and fecal steroid measurements for monitoring ovarian function and pregnancy in the bonobo (Pan paniscus) and evaluation of perineal swelling patterns in relation to endocrine events. - Biol. Reprod. 55: 844-853.

Hendrickx, A.G. \& Kraemer, D.C. (1969). Observations on the menstrual cycle, optimal mating time and pre-implantation embryos of the baboon, Papio anubis and Papio cynocephalus. - J. Reprod. Fertil. Suppl. 6: 119-128.

Henzi, S.P. \& Barrett, L. (1999). The value of grooming to female primates. - Primates 40: 47-59.

Hill, D.A. (1987). Social relationships between adult male and female rhesus macaques: 1. Sexual consortships. - Primates 28: 439-456.

Hohmann, G. \& Fruth, B. (2000). Use and function of genital contacts among female bonobos. - Anim. Behav. 60: 107-120.

Hohmann, G., Gerloff, U., Tautz, D. \& Fruth, B. (1999). Social bonds and genetic ties: kinship, association and affiliation in a community of bonobos (Pan paniscus). - Behaviour 136: 1219-1235.

Hrdy, S.B. \& Whitten, P.L. (1987). Patterning of sexual activity. — In: Primate societies (Smuts, B.B., Cheney, D.L., Seyfarth, R.M., Wrangham, R.W. \& Struhsaker, T.T., eds). University of Chicago Press, Chicago, IL, p. 370-384.

Idani, G. (1991). Social relationships between immigrant and resident bonobo (Pan paniscus) females at Wamba. - Folia Primatol. 57: 83-95.

Jolly, A. (1966). Lemur behavior: a Madagascar field study. — University of Chicago Press, Chicago, IL.

Kano, T. (1982). The social group of pygmy chimpanzees (Pan paniscus) of Wamba. Primates 23: 171-188.

Kano, T. (1992). The last ape: pygmy chimpanzee behavior and ecology. — Stanford University Press, Stanford, CA.

Kuroda, S. (1979). Grouping of the pygmy chimpanzees. — Primates 20: 161-183.

Kuroda, S. (1980). Social behavior of the pygmy chimpanzees. — Primates 21: 181-197.

McKenna, J.J. (1978). Biosocial functions of grooming behavior among the common Indian langur monkey (Presbytis entellus). — Am. J. Phys. Anthropol. 48: 503-509.

Mulavwa, M.N., Furuichi, T., Yangozene, K., Yamba-Yamba, M., Motema-Salo, B., Idani, G., Ihobe, H., Hashimoto, C., Tashiro, Y. \& Mwanza, N. (2008). Seasonal changes in fruit production and party size of bonobos at Wamba. — In: The bonobos (Furuichi, T. \& Thompson, J., eds). Springer, New York, NY, p. 121-134.

Mulavwa, M.N., Yangozene, K., Yamba-Yamba, M., Motema-Salo, B., Mwanza, N.N. \& Furuichi, T. (2010). Nest groups of wild bonobos at Wamba: selection of vegetation and tree species and relationships between nest group size and party size. - Am. J. Primatol. 72: $575-586$. 
Muller, M.N., Kahlenberg, S.M., Emery Thompson, M. \& Wrangham, R.W. (2007). Male coercion and the costs of promiscuous mating for female chimpanzees. - Proc. Roy. Soc. Lond. B: Biol. Sci. 274: 1009-1014.

Nunn, C.L. (1999). The evolution of exaggerated sexual swellings in primates and the gradedsignal hypothesis. - Anim. Behav. 58: 229-246.

Pagel, M. (1994). The evolution of conspicuous oestrous advertisement in Old World monkeys. - Anim. Behav. 47: 1333-1341.

Paoli, T. (2009). The absence of sexual coercion in bonobos. - In: Sexual coercion in primates and humans: an evolutionary perspective on male aggression against females (Muller, M.N. \& Wrangham, R.W., eds). Harvard University Press, Cambridge, MA, p. 410-423.

Paoli, T., Palagi, E., Tacconi, G. \& Tarli, S.B. (2006). Perineal swelling, intermenstrual cycle, and female sexual behavior in bonobos (Pan paniscus). - Am. J. Primatol. 68: 333-347.

Parish, A.R. (1994). Sex and food control in the "uncommon chimpanzee": how bonobo females overcome a phylogenetic legacy of male dominance. - Ethol. Sociobiol. 15: 157-179.

Parish, A.R. (1996). Female relationships in bonobos (Pan paniscus): evidence for bonding, cooperation, and female dominance in a male-philopatric species. — Hum. Nat. 7: 61-96.

Parish, A.R., de Waal, F.B.M. \& Haig, D. (2000). The other "closest living relative": how bonobos (Pan paniscus) challenge traditional assumptions about females, dominance, intra- and intersexual interactions, and hominid evolution. - Ann. NY Acad. Sci. 907: 97-113.

Pinheiro, J., Bates, D., DebRoy, S., Sarkar, D. \& R Core Team (2012). nlme: linear and nonlinear mixed effects models. - R Core Team, Vienna.

Pocock, R.I. (1906). Notes upon menstruation, gestation, and parturition of some monkeys that have lived in the Society's Gardens. - Proc. Zool. Soc. Lond.: 558-570.

R Core Team (2012). R: a language and environment for statistical computing. — R Foundation for Statistical Computing, Vienna.

Reichert, K.E., Heistermann, M., Hodges, J.K., Boesch, C. \& Hohmann, G. (2002). What females tell males about their reproductive status: are morphological and behavioural cues reliable signals of ovulation in bonobos (Pan paniscus)? — Ethology 108: 583-600.

RStudio (2012). RStudio: integrated development environment for R. - RStudio, Boston, MA.

Saayman, G.S. (1970). The menstrual cycle and sexual behaviour in a troop of free ranging chacma baboons (Papio ursinus). — Folia Primatol. 12: 81-110.

Sakamaki, T. (2013). Social grooming among wild bonobos (Pan paniscus) at Wamba in the Luo Scientific Reserve, DR Congo, with special reference to the formation of grooming gatherings. - Primates 54: 349-359.

Sakug, H., Fournier, D., Nielsen, A., Magnusson, A. \& Bolker, B. (2012). Generalized linear mixed models using AD Model Builder.

Savage-Rumbaugh, E.S. \& Wilkerson, B.J. (1978). Socio-sexual behavior in Pan paniscus and Pan troglodytes: a comparative study. - J. Hum. Evol. 7: 327-344. 
Sbeglia, G.C., Tang-Martinez, Z. \& Sussman, R.W. (2010). Effects of food, proximity, and kinship on social behavior in ringtailed lemurs. — Am. J. Primatol. 72: 981-991.

Seyfarth, R.M. (1977). A model of social grooming among adult female monkeys. J. Theor. Biol. 65: 671-698.

Silk, J.B., Alberts, S.C. \& Altmann, J. (2003). Social bonds of female baboons enhance infant survival. - Science 302: 1231-1234.

Smuts, B.B. \& Smuts, R.W. (1993). Male aggression and sexual coercion of females in nonhuman primates and other mammals: evidence and theoretical implications. - Adv. Stud. Behav. 22: 1-63.

Spruijt, B.M., van Hooff, J.A.R.A.M. \& Gispen, W.H. (1992). Ethology and neurobiology of grooming behavior. - Physiol. Rev. 72: 825-852.

Surbeck, M., Mundry, R. \& Hohmann, G. (2011). Mothers matter! Maternal support, dominance status and mating success in male bonobos (Pan paniscus). — Proc. Roy. Soc. Lond. B: Biol. Sci. 278: 590-598.

Takahata, Y., Ihobe, H. \& Idani, G. (1996). Comparing copulations of chimpanzees and bonobos: do females exhibit proceptivity or receptivity? - In: Great ape societies (McGrew, W.C., Marchant, L.F., Nishida, T., Goodall, J. \& Itani, J., eds). Cambridge University Press, Cambridge, p. 146-155.

Thompson-Handler, N., Malenky, R.K. \& Badrian, N. (1984). Sexual behavior of Pan paniscus under natural conditions in the Lomako Forest, Equateur, Zaire. - In: The pygmy chimpanzee (Susman, R.L., ed.). Springer, New York, NY, p. 347-368.

Tokuda, K. (1961). A study on the sexual behavior in the Japanese monkey troop. — Primates 3: $1-40$.

van Schaik, C.P., Hodges, J.K. \& Nunn, C.L. (2000). Paternity confusion and the ovarian cycles of female primates. - In: Infanticide by males and its implications (van Schaik, C.P. \& Janson, C.H., eds). Cambridge University Press, Cambridge, p. 361-387.

Wallis, J. (1992). Chimpanzee genital swelling and its role in the pattern of sociosexual behavior. - Am. J. Primatol. 28: 101-113.

White, F.J. (1988). Party composition and dynamics in Pan paniscus. - Int. J. Primatol. 9: 179-193.

Wickham, H. (2002). The split-apply-combine strategy for data analysis. - J. Stat. Softw. 40: 1-29.

Wickham, H. (2009). ggplot2: elegant graphics for data analysis. - Springer, New York, NY.

Wildt, D.E., Doyle, L.L., Stone, S.C. \& Harrison, R.M. (1977). Correlation of perineal swelling with serum ovarian hormone levels, vaginal cytology, and ovarian follicular development during the baboon reproductive cycle. - Primates 18: 261-270.

Wright, P.C., Izard, M.K. \& Simons, E.L. (1986). Reproductive cycles in Tarsius bancanus. — Am. J. Primatol. 11: 207-215.

Young, C., Majolo, B., Heistermann, M., Schülke, O. \& Ostner, J. (2013). Male mating behaviour in relation to female sexual swellings, socio-sexual behaviour and hormonal changes in wild Barbary macaques. - Horm. Behav. 63: 32-39. 
Zeileis, A. \& Hothorn, T. (2002). Diagnostic checking in regression relationships. - R News 2: 7-10.

Zinner, D.P., Nunn, C.L., van Schaik, C.P. \& Kappeler, P.M. (2004). Sexual selection and exaggerated sexual swellings of female primates. - In: Sexual selection in primates (van Schaik, C.P., ed.). Cambridge University Press, New York, NY, p. 71-89.

Zuckerman, S. \& Fulton, J.F. (1934). The menstrual cycle of the primates: Part VII. The sexual skin of the chimpanzee. - J. Anat. 69: 38-47.

Zuur, A.F., Ieno, E.N., Walker, N.J., Saveliev, A.A. \& Smith, G.M. (2009). Mixed effects models and extensions in ecology with R. - Springer, New York, NY. 